\title{
Science Research
}

2019; 7(3): 33-37

$\mathrm{http}: / / \mathrm{www} \cdot$ sciencepublishinggroup.com/j/sr

doi: 10.11648/j.sr.20190703.11

ISSN: 2329-0935 (Print); ISSN: 2329-0927 (Online)

\section{Sexual Knowledge and Experience of Women with Spinal Cord Injury in the Community Level in Bangladesh}

\author{
Mst. Fatema Akter ${ }^{1}$, Ehsanur Rahman ${ }^{1}$, Md. Obaidul Haque ${ }^{1}$, Mohammad Habibur Rahman ${ }^{2}$ \\ ${ }^{1}$ Department of Physiotherapy, Bangladesh Health Professions Institute (BHPI), Centre for the Rehabilitation of the Paralysed (CRP), \\ Bangladesh \\ ${ }^{2}$ School of Science and Technology, Bangladesh Open University, Gazipur, Bangladesh
}

Email address:

ehsanurrahman09@gmail.com (E. Rahman)

\section{To cite this article:}

Mst. Fatema Akter, Ehsanur Rahman, Md. Obaidul Haque, Mohammad Habibur Rahman. Sexual Knowledge and Experience of Women with Spinal Cord Injury in the Community Level in Bangladesh. Science Research. Vol. 7, No. 3, 2019, pp. 33-37.

doi: 10.11648/j.sr.20190703.11

Received: August 15, 2019; Accepted: September 19, 2019; Published: September 30, 2019

\begin{abstract}
Sexual knowledge is an important part of every life and it is necessary for clinicians to have a specific format in which to address sexual issues with their patients. A systematic approach to working with female spinal cord injury (SCI) patients need to present their sexual knowledge and experience. To explore the sexual knowledge and experience of women with spinal cord injury in the community level. The researcher conducted a mixed method research. In order to assess sexuality a standard questionnaire was developed on the basis of the clinical experience and review of relevant literature. The items of the questionnaire were selected keeping in mind the complex culture and principles of our society. VAS scale and likert scale was used to measure 9 close questions related to sexual knowledge and experience. Another 2 open ended question explored their perception how they maintain good relation and what they want to know from the rehabilitation program. Paired ' $t$ ' test was used for identify the quality of sexual life. The total participant was 30. Mean ages were $30.73 \pm 7.47$ years. Mean duration of injury was 7.733 years. Of the participants 17 (56.7\%) live in rural and 13 (43.3\%) live in urban. The participant 23 (76.7\%) was married before injury, 7 (23.3\%) was married after injury. The study result was who stay in urban area their sexual happiness means score (54.384) was more than who stay in rural area (35.47). Married after injury (7 women) their mean sexual happiness score (72\%) was more than who was married (23 women) before injury (mean score 33.82 ) and Significantly difference $(\mathrm{P}<0.05)$ quality of sexual life before and after injury. $50 \%$ of participant indicated that support of husband was not much and not at all. Advice from the participants for maintaining good relationship, financial independence, self-confidence, copes with the present situation is important. Participants want to know proper guidance after operation and different individual problem-solving technique in the rehabilitation education program. This study present important information with regards for improving sexual rehabilitation services to women with SCI.
\end{abstract}

Keywords: Sexual Knowledge, Sexual Experience, Women with Spinal Cord Injury, Community

\section{Introduction}

Sexuality is a fundamental right of every individual [1]. Current literature on sexuality following spinal cord injury focuses largely on men but little attention given on women [2]. Fritz et al [3] reported that in rehabilitation women are not receiving appropriate attention about the knowledge of sexuality. Healthy adjustment depends on sexual satisfaction and self-esteem [4]. Moreno- Lozano et al [5] said that walking is not always the most important function to recover in order to improve their quality of life but return to their sexual relation is needed to improve future quality of life. No study was reported sexuality of women with spinal cord injury In Bangladesh. Most of the women are willing to receive information about sexuality after SCI. They expected their rehabilitation service provider start to talk about this area rather than asking about it. Spinal cord injury changes the life style and they need to know how to cope with their life [6]. Knowledge about altered sexuality which goes beyond fertility topics to promote an enjoyable sexual life [7]. Maasoumi et al [8] found that in Iranian women with complete spinal cord injury reported that their rehabilitation team provides a little information for their sexuality understanding need through educational program. Courtois et al [9] report that education about these issues to help adapt to their new lives and to maintain a positive attitude toward sexual 
health and motherhood. Sexuality is vital in the process of accepting and coping with SCI and highlighted the importance of reproduction for women in general, before and after SCI, were also prominent [10]. Aikman et al [11] reported that lack of sexual rehabilitation services and consensus around clinician roles, and societal stigmas related to disability and sexuality obstruct treatment.

\section{Methodology}

The study conducted a mixed method of research design. Nine structured questionnaires were used for quantitative measure and two unstructured questions were used for qualitative measure. The female with SCI who were married selected conventionally. One to one interview was carried out by the data collectors through face to face interview in the community. VAS scale, likert scale used to explore sexual experience and knowledge. Paired ' $t$ ' test was used to assess the quality of sexual life before and after SCI. This study was approved by the ethical committee of Bangladesh Health Professions Institute (BHPI), academic institute of Centre for the rehabilitation of the paralysed (CRP). The study was conducted from June 2017 to May 2018. In the Questionnaire Clinical characteristics was evaluated by using ASIA
(American Spinal Injury Association) impairment scale. VAS and Likert scale were used to identify happiness of sexual life, quality of sexual life before and after, importance of sexual life to their husband, identify their knowledge. Paired ' $t$ ' test was used for evaluating the quality of sexual life before and after injury. Two open ended question explored their perception how they maintain good relation and what they want to know from the rehabilitation program.

\section{Results}

The total participant was 30. Mean ages of them were $30.73 \pm 7.47$ years. Mean duration of injury was 7.733 years. The total participant among them stay with husband 20 (66.7\%), Of the participants $17(56.7 \%)$ live in rural and 13 $(43.3 \%)$ live in urban. The majority of the participants educational level was Secondary level 13 (43.3\%). 12 (40\%) participant has no child, 15 (50\%) participant had child before injury, $3(10 \%)$ participant had child after injury. The participant $23(76.7 \%)$ was married before injury, 7 (23.3\%) was married after injury. Based on the American spinal injury association impairment scale most of the participant was ASIA A (Complete) 12 (40\%).

Table 1. Socio-demographic characteristics of women with spinal cord injury.

\begin{tabular}{|c|c|c|c|}
\hline Socio demographic characteristics & Number (\%) & Presence of child & $\mathbf{N}(\%)$ \\
\hline Age (Mean, SD) & $30.73 \pm 7.47$ & Child present before injury & $15(50 \%)$ \\
\hline Duration of injury (mean, yrs) & 7.733 & Child present after injury & $3(10 \%)$ \\
\hline Marital status & $\mathrm{N}(\%)$ & No child & $12(40 \%)$ \\
\hline Stay with husband & $20(66.7 \%)$ & When married & $\mathrm{n}(\%)$ \\
\hline Separate & $8(26.7 \%)$ & Before injury & $23(76.7 \%)$ \\
\hline Divorce & $2(6.7 \%)$ & After injury & $7(23.3 \%)$ \\
\hline Living Area & $\mathrm{N}(\%)$ & ASIA Impairment scale & $\mathrm{n}(\%)$ \\
\hline Urban & $13(43.3 \%)$ & ASIA-B & $7(23.3 \%)$ \\
\hline Educational Level, & $\mathrm{N}(\%)$ & ASIA-C & $4(13.3 \%)$ \\
\hline Higher & $6(20 \%)$ & ASIA-D & $7(23.3 \%)$ \\
\hline Secondary & $13(43.3 \%)$ & & \\
\hline Primary & $8(26.7 \%)$ & & \\
\hline No education & $3(10 \%)$ & & \\
\hline
\end{tabular}

\subsection{Happiness of Sexual Life Experience at the Moment-VAS Scale (0-100)}

The present happiness of sexual life experience mean score was less than 50 in different situation.

Table 2. Happiness of sexual life experience at the moment of female spinal cord injury patient in the community.

\begin{tabular}{ll}
\hline Happiness of sexual life & Mean \\
\hline Physical and mental desires, personal feelings & 44.83 \\
Kissing, caressing, hugging & 43.66 \\
Sexual intercourse & 46 \\
Becoming pregnant and getting children & 39.50 \\
Being kind to the desires of husband & 44.33 \\
\hline
\end{tabular}

\subsection{Sexual Happiness According to Their Living Area}

The figure 1 below shows that who stay in urban area their sexual happiness mean score was 54.384 and who stay in rural area their sexual happiness mean score was 35.47.

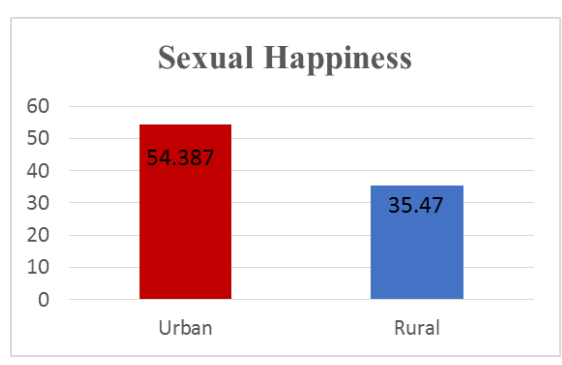

Figure 1. Sexual happiness according to their living area.

\subsection{Sexual Happiness According to Their Marital Time Before \& After Injury}

The figure 2 below show that who was married after injury ( 7 women) their mean sexual happiness score was 72 and who were married before injury ( 23 women) their sexual happiness mean score was 33.82 at the moment. 


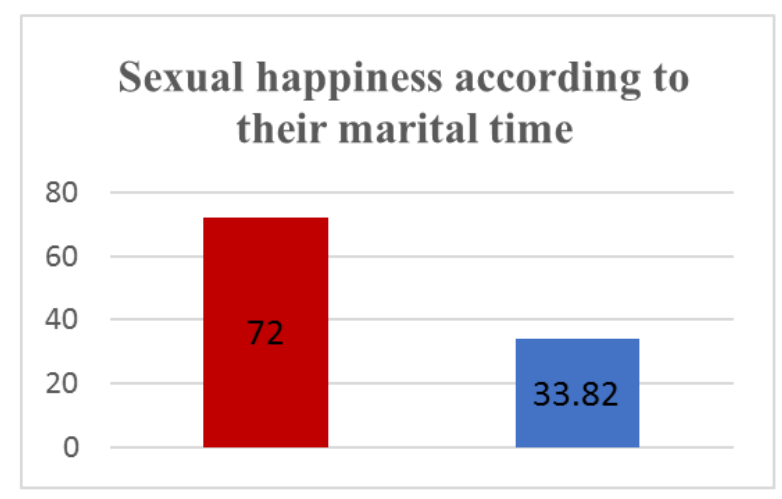

Figure 2. Sexual happiness according to their marital time before \& after.

\subsection{Quality of Sexual Life (Before \& After Injury)}

The table 3 below shows that the mean difference of quality of sexual life before SCI and after SCI was 4.34. P value was $\mathrm{p}<0.05$. There was significant difference of their quality of sexual life before injury and after injury.

Table 3. Quality of sexual life before SCI and after SCI Paired Sample ' $t$ ' Test.

\begin{tabular}{lllll}
\hline & Mean T & Df & Sig (2-tailed) \\
\hline Quality of sexual life before and after & 4.34 & 6.506 & 21 & .000 \\
\hline
\end{tabular}

\subsection{Support of Husband in Daily and Sexual Life}

The below figure 3 showed that maximum subjects 15
$(50 \%)$ didn't get help not much and not at all support from husband. Moreover, 9 (30\%) indicated that support of their husband was much and very much. $6(20 \%)$ indicated support of their husband was average.

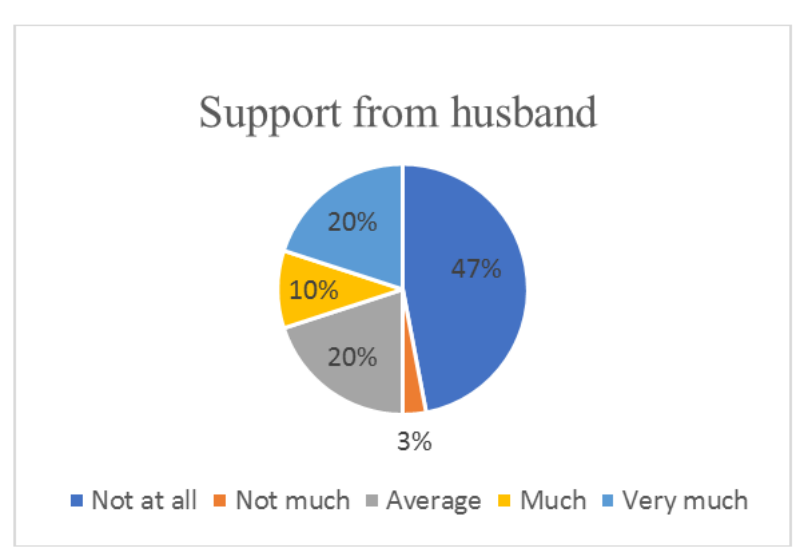

Figure 3. Support of husband in daily and sexual life.

\subsection{Knowledge About Sexual Relation of Female Spinal Cord Injury Patients}

This table 4 shows that highest subjects rated $12(40 \%)$ know they were able to become pregnant, $13(43.3 \%)$ indicated able to give birth to a healthy child, $10(33.3 \%)$ indicated yes able give birth in a safe way, 14 (46.7\%) indicated they can able to sexually satisfy to their husband.

Table 4. Knowledge about sexual relation of 30 female spinal cord injury patients.

\begin{tabular}{lllll}
\hline Knowledge & Absolutely able & Yes able & Don't know & Perhaps able \\
\hline Able to pregnant & $16.7 \%$ & $40 \%$ & $16.7 \%$ & $23.3 \%$ \\
Able to birthhealthy child & $10 \%$ & $43.3 \%$ & $16.7 \%$ & $26.66 \%$ \\
Give birth safe way & $10 \%$ & $33.3 \%$ & $16.7 \%$ & $3.3 \%$ \\
Sexually satisfy your husband & $10 \%$ & $46.7 \%$ & $13.3 \%$ & $26.66 \%$ \\
\hline
\end{tabular}

\subsection{Advice to the Women to Build Good Relation with Their Husband}

Advice for the good relationship with their husband, as we can identify in the speech of one interviewer:

"Yes, after injury we must be independent, not only activity of daily living but also financial."

Seven interviewers said that before injury they were house wife but after injury, they found that sometime they need extra medical care. Usually most of them has financial problem. Their family feels extra burden with them.

Some interviewees reported that for good relation with their husband after injury:

"Make self-confidence, cope with the present situation, motivated our husband."

\subsection{Wish to Hear \& Learn About Sexual Life of Women with SCI in the Rehab Program}

From the interviewees statement they wish to hear and learn about sexual life from the rehabilitation program

"I was confused after operation. Can I involve myself in sexual relation? No one health profession gave me clear information. I was afraid; it will be worse my operation. Met with local doctor, but she did not assure me to involve in the relation after operation. I want learn the proper guidance after operation for making the sexual relation.",

\section{Discussion}

\subsection{Happiness of Sexual Life}

This study discovered the present happiness of sexual life mean score below half of the normal range. Another research showed that subjects labelled their sex lives as worse after SCI, largely due to difficulties in their relationship with their partner, medical problems and the lack of privacy [10]. In contrast another study revealed that sexual function and SCI shows that sexual pleasure are possible for women having spinal cord injury [9]. Sexuality is expressed in different ways, namely by desires, feelings, thoughts, emotions, attitudes, and behaviors, influenced by cultural context and historical moments [12].

\subsection{Quality of Sexual Life (Before \& After Injury)}

This study found that quality of sexual life significantly decreases after spinal cord injury and some of subjects were separated and divorce. In relate to this finding other researcher revealed that quality of sexual life depends on age of patient, duration of SCI, completeness of SCI, continence and having a partner were identified as an active sex life [13]. 
In another study discovered that compared their sexual experiences from pre-and post-SCI and described that their sexual ability was decreased as well as quality of sexual life was also decreased [12]. Other study comparing the sexuality of women with SCI before and after injury it was found a significant lowering in sexual desire, impaired lubrication and worsened ability of sexual activity [14].

\subsection{Support of Husband}

This study found that maximum female patient anxious of not being received supportive help from their husband in daily life and sexual life activity. In one study, in which support of partner is necessary for happiness, fulfillment, and connectedness with other; This research also claimed that desire discrepancy was defined as the difference in desire between sexual partners, low discrepancy was positively related to both relationship and sexual satisfaction [15]. In another research discovered that women with SCI fear abandonment by their husband or the possibility of never having another relationship; however, these fears soon fade by their husband's acceptance of disability [10].

\subsection{Knowledge from Rehabilitation Program}

Knowledge about sexuality after spinal cord injury is an important step toward making a healthy adjustment. In study most of the participant know that they are able to become pregnant with SCI, able to give birth to a healthy child with SCI and able to satisfy their husband. But they do not confidently know the absolute able to those functions. In related to this finding one study recommended that to understand about women's sexuality, reproductive health and to learn about the options that are available for a safe pregnancy, labor, delivery and it should be addressed during rehabilitation [9].

\subsection{Advice Comes from the Participant to Make Good Relation with Their Husband}

Usually in the developing country community people feels double burden with them. This study found the key information that financial independence is necessary for making a good relationship and quality of life. For maintaining the good relation with family member as well as their husband showed their participation, activity and motivated to their own activity. Always try to cope with the present situation and influence their husband to maintain a good relation. In relate to other study women's altered sexuality caused difficulties for some partners and also woman's inability to orgasm could be construed as personal failure [7].

\subsection{Hear and Learn from the Rehabilitation Program}

The key information was found from the participant that there was little attention provide in sexual educational class. In the community level they do not get any solution from the doctor. So, they want clear information about the reproductive sexual relationship after operation which they did not ask in the educational program. Another study finds that some of the female spinal cord injured patients did not know how to be sexually active again to promote their sexual relationship [8].

Some of participant felt they need problem solving educational class. Participants felt that healthcare professionals (HCPs) lack knowledge, are too embarrassed to discuss sex. One qualitative study among women with SCI living in the community in United Kingdom (UK) and recommended thatwomen wanted HCPs to be knowledgeable and approachable about sexuality; in education about sexuality after SCI, participants wanted more emphasis on reproduction rather than on enjoyment and the emotional aspects of sex [7]. Another qualitative study was conductedamong twenty four SCI women participants and clearlymentioned that a rehabilitation team is needed to inform about sexuality changes of post SCI injury therefore sexuality education and counselling started soon after being diagnosed [8].

\section{Limitation}

The sample size is small. Study expressed that it has gained some knowledge from the data that is relevant in improving sexual rehabilitation service for the women with SCI. A limitation of this study is the difficulty displayed by participants when talking about the issue, given its highly personal and intimate nature.

\section{Conclusion}

Sexuality remainders a significant, valued aspect of female identity following SCI; sexual activity continues and though altered remains enjoyable and rewarding. Sexuality rehabilitation should commence early, preparing women for altered sexual sensation, disclosure of altered sexual function to partners, and encouraging early self-exploration.

\section{Recommendations}

Thus, further research is suggested to address the aspects involved in the sexuality and reproduction of women after SCI, since the information obtained could contribute to educational and healthcare initiatives to improve sexual rehabilitation services for the women with SCI.

\section{References}

[1] Parker MG, Yau MK. Sexuality, identity and women with spinalcord injury. Sexuality and Disability. 2012; 30: 15-27.

[2] Kreuter M, Taft C, Siösteen A, Biering-Sørensen F. Women'ssexual functioning and sex life after spinal cord injury. SpinalCord. 2011; 49: 154-60.

[3] Fritz HA, Dillaway H, Lysack CL."Don't think paralysis takesaway your womanhood": sexual intimacy after spinal cord injury. Am J Occup Ther. 2015; 69: 1-10.

[4] Otero-Villaverde S, Ferreiro-Velasco ME, Montoto-Marqués A, Salvador de la Barrera S, Arias-Pardo AI, RodriguezSotillo A. Sexual satisfaction in women with spinal cord injuries. Spinal Cord. 2015; 53: 557-60. 
[5] Moreno-Lozano M, Duran-Ortiz S, Perez-Zavala R, Quinzanos-Fresnedo J. Sociodemographic factors associated with sexual dysfunction in Mexican women with spinal cord injury. Spinal cord. 54 (9): 746; 2016.

[6] Khazaeipour Z, Taheri-Otaghsara SM, Naghdi M., (2015) Depression Following Spinal Cord Injury: Its Relationship to Demographic and Socioeconomic Indicators. Top Spinal Cord Inj Rehabil.; 21 (2): 149-55. doi: 10.1310/sci2102-149. [PubMed: 26364284].

[7] Thrussell H, Coggrave M, Graham A, Gall A, Donald M, Kulshrestha R, Geddis T. Women's experiences of sexuality after spinal cord injury: a UK perspective. Spinal cord. 2018 Nov; 56 (11): 1084.

[8] Maasoumi R, Zarei F, Razavi SH, Khoei EM. How Iranian women with spinal cord injury understand sexuality. Trauma Monthly. 22 (3); 2017.

[9] Courtois F, Alexander M, McLain AB. Women's sexual health and reproductive function after SCI. Topics in spinal cord injury rehabilitation. 2017 Dec; 23 (1): 20-30.

[10] Ferreira DV, Matão ME. Sexuality and reproduction in women with spinal cord injury. Fisioterapia em Movimento. 2017 Dec; 30 (4): 733-44.
[11] Aikman K, Oliffe JL, Kelly MT, McCuaig F. Sexual Health in Men with Traumatic Spinal Cord Injuries: A Review and Recommendations for Primary Health-Care Providers. American journal of men's health. 2018 Nov; 12 (6): 2044-54.

[12] Torriani SB, Britto FC, da Silva GA, de Oliveira DC, de Figueiredo Carvalho ZM. Sexuality of people with spinal cord injury: Knowledge, difficulties and adaptation. Journal of Biomedical Science and Engineering. 7 (06): 380; 2014.

[13] Gomes CM, Miranda EP, de Bessa Jr J, Bellucci CH, Battistella LR, Abdo CH, Bruschini H, Srougi M, Mulhall JP. Erectile function predicts sexual satisfaction in men with spinal cord injury. Sexual medicine. 2017 Sep 1; 5 (3): e14855 .

[14] Sramkova T, Shrivanova k, Dolan L, Zamecnik L, Sramkova K, Kriz J, Muzik V, Fajtova R. Women's Sex life after spinal cord injury. Sexual Medicine. 2017 July; 5: e255-e259

[15] Velten J, Margraf J. Satisfaction guaranteed? How individual, partner, and relationship factors impact sexual satisfaction within partnerships. Plos one. 2017 Feb 23; 12 (2): e0172855. 